\title{
Fossils challenge DNA in the dating game
}

Yet again, molecules and fossils are at odds in the dating of a key event in the history of life. On page 1003 of this issue, palaeontologist John Wible of the Carnegie Museum of Natural History in Pittsburgh, Pennsylvania, and his colleagues use their discovery of a Cretaceous mammal from Mongolia to build the most complete fossil-based mammal family tree so far. It suggests that modern mammals arose only after the dinosaurs went extinct 65 million years ago, thus contradicting dates derived from the DNA of living mammals including another recent Nature paper (O. R. Bininda-Edwards et al. 406, 507-512; 2007). In the DNA analyses, modern groups appear earlier, between 100 and 80 million years ago, with the extinction of the dinosaurs seeming to have had little effect on their evolution.

Yawning gaps between molecular and palaeontological approaches to the dating of evolutionary landmarks have appeared ever since molecular approaches based on DNA sequences first became widely used about 15 years ago. When results differ, the molecular technique almost always pushes events further back than the fossil record. For example, some molecular studies estimate that multicellular animals arose about a billion years ago, but the fossil record goes back a mere 600 million years. Fossil plant spores date back 475 million years, but molecular dates put plants on land 700 million years ago.

However, there are signs that this deep-running discord may be being resolved, at least in some cases. "Ten years ago the divide looked very sharp," says palaeontologist Mike Benton of the University of Bristol, UK. "But there's been a certain amount of movement both ways - palaeontological and molecular people are moving towards one another."

That molecular dates are a little earlier is to be expected. DNA should record the moment that a lineage split, but the imperfections of the fossil record mean that the first preserved post-split organisms will date from later on. And there are some groups - such as the microscopic, soft-bodied animals that make up about half the extant animal phyla - that have no fossil record at all. "We should be willing to accept biases in the fossil record regarding certain types of animal," says Blair Hedges of Pennsylvania State University in University Park. Hedges has been among the most vigorous advocates of earlier DNA dates for major evolutionary splits, including those that produced the animals, the land plants, the fungi and mammals.

But although Kevin Peterson of Dartmouth College in Hanover, New Hampshire, agrees that some groups' fossil records are too patchy to be trusted, he is scathing of the notion that the first animals could have gone unfossilized for nearly half a billion years. "To say that because the record is incomplete you can have a

\section{Quarter of deaths from environment are avoidable}

Living in an unhealthy environment kills many times more people than die in road accidents, violent conflicts and natural disasters put together, but these risks rarely make headlines. Now an analysis by the World Health Organization (WHO) reveals that about a quarter of the annual health and death toll of living in such environments could be avoided.

The report is the result of an eightyear meta-analysis of relevant scientific literature and available health and population statistics, which went through the fraction of mortality and illness attributable to environmental causes factor by factor. More than 100 public-health experts and epidemiologists advised on the regional health impacts.

Polluted water, poor sanitation and smoke inhalation resulting from indoor use of wood-burning stoves are the main risks in most low-income countries, and poverty is a major obstacle when it comes to reducing risk exposure. But environmental factors pose an avoidable health risk in rich countries as well, says Annette Prüss, a
WHO public-health scientist who oversees the project. Noise, work stress and outdoor pollution all add to the burden of ill health attributable to the environment.

The WHO's research centres on 'disability adjusted life years' (DALY) that are preventable through healthier environments. The DALY is a commonly used unit that includes years lost when someone dies prematurely and also takes account of years blighted by chronic disease or disability. The data, says Prüss, are to help national health authorities prioritize disease prevention efforts. "Most countries, rich and poor, haven't yet realized that severe health problems often have quite trivial causes," she says.

"The WHO exercise is helpful in that it draws attention to the fact that many health problems need a non-medical response," says Andrew Scott, policy director with Practical Action, a nongovernmental organization that helps modernize cooking stoves in Africa. "Small amounts can make a large difference." Quirin Schiermeier

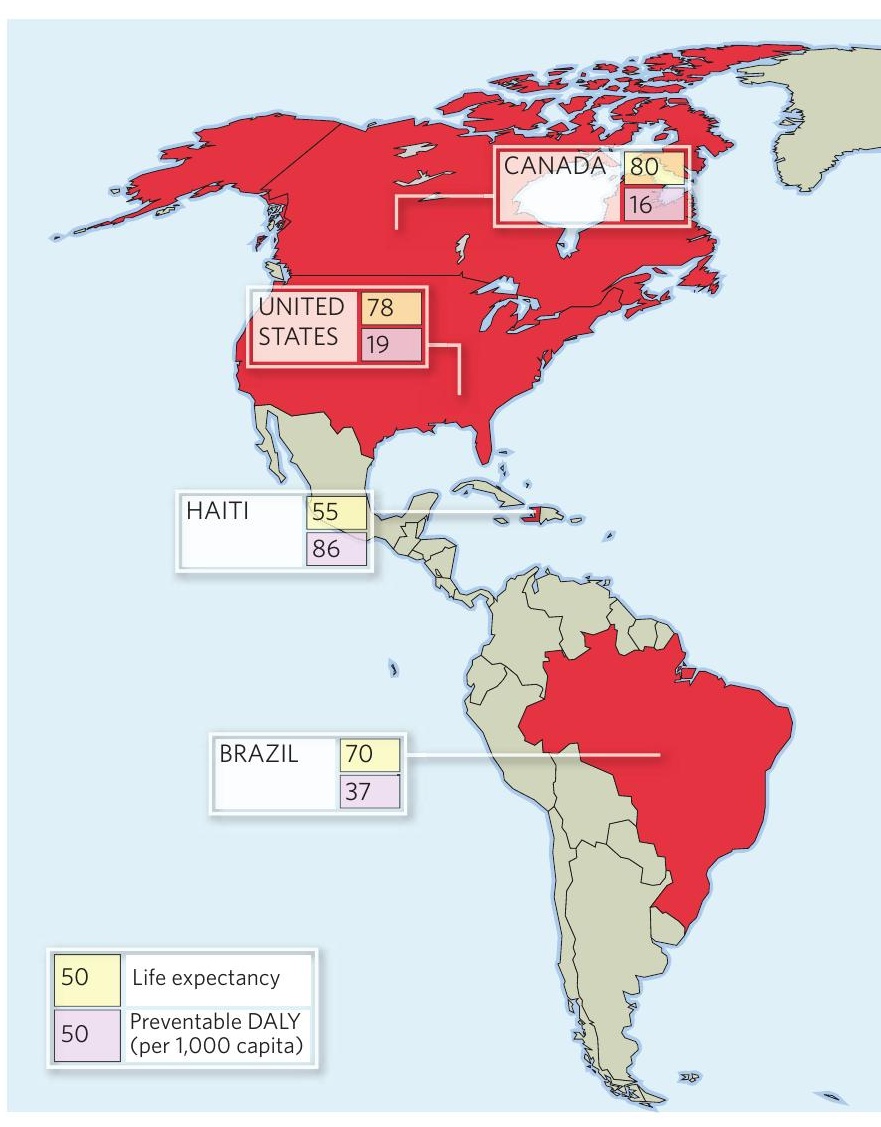


billion-year-old bilaterian is a woeful misunderstanding of the fossil record," he says.

DNA clocks have their own problems, which can cause overestimates of the age of evolutionary splits. Different genes can evolve at different rates, and the calibration of DNA clocks must be handled carefully. A calibration that involves a slowly evolving lineage can throw a whole tree off.

Benton sees hope in new statistical methods that can better account for uncertainty in both the timing of calibration points

"The flexibility is hugely liberating I see a glowing future for this." and measurements of evolutionary rates. In such treatments, both fossil and molecular dates go from being fixed points with error bars to being a range of probabilities. "The flexibility is hugely liberating," says Benton. "I see a glowing future for this."

Using such an approach, Peterson has obtained molecular dates for the origin of the animals that match their first appearance in the fossil record (K. J. Peterson \& N. J. Butterfield, Proc. Natl. Acad. Sci. USA 102, 9547-9552; 2005). He presented his latest analyses this week at a meeting at the Royal Society in London. "All of the latest estimates are putting the division of the bilateria right in the Ediacaran," he says, referring to the geological period predating the Cambrian explosion of about 540 million years ago. A group led by Emmanuel Douzery at the University of Montpelier in France has got similar results in the past few years. Hedges argues, however, that these more recent dates are the result of calibration errors.

The mammals look to be a tougher nut to crack. "I don't have a good answer as to why there's this discrepancy," says Wible, "but I doubt our work is the final answer." He is part of a project funded by the US National Science Foundation to combine molecular and morphological data to build the most complete mammal tree so far. "We need to marry the data sets together," he says. "Only this type of analysis can address these major problems."

John Whitfield

See News \& Views, page 918.

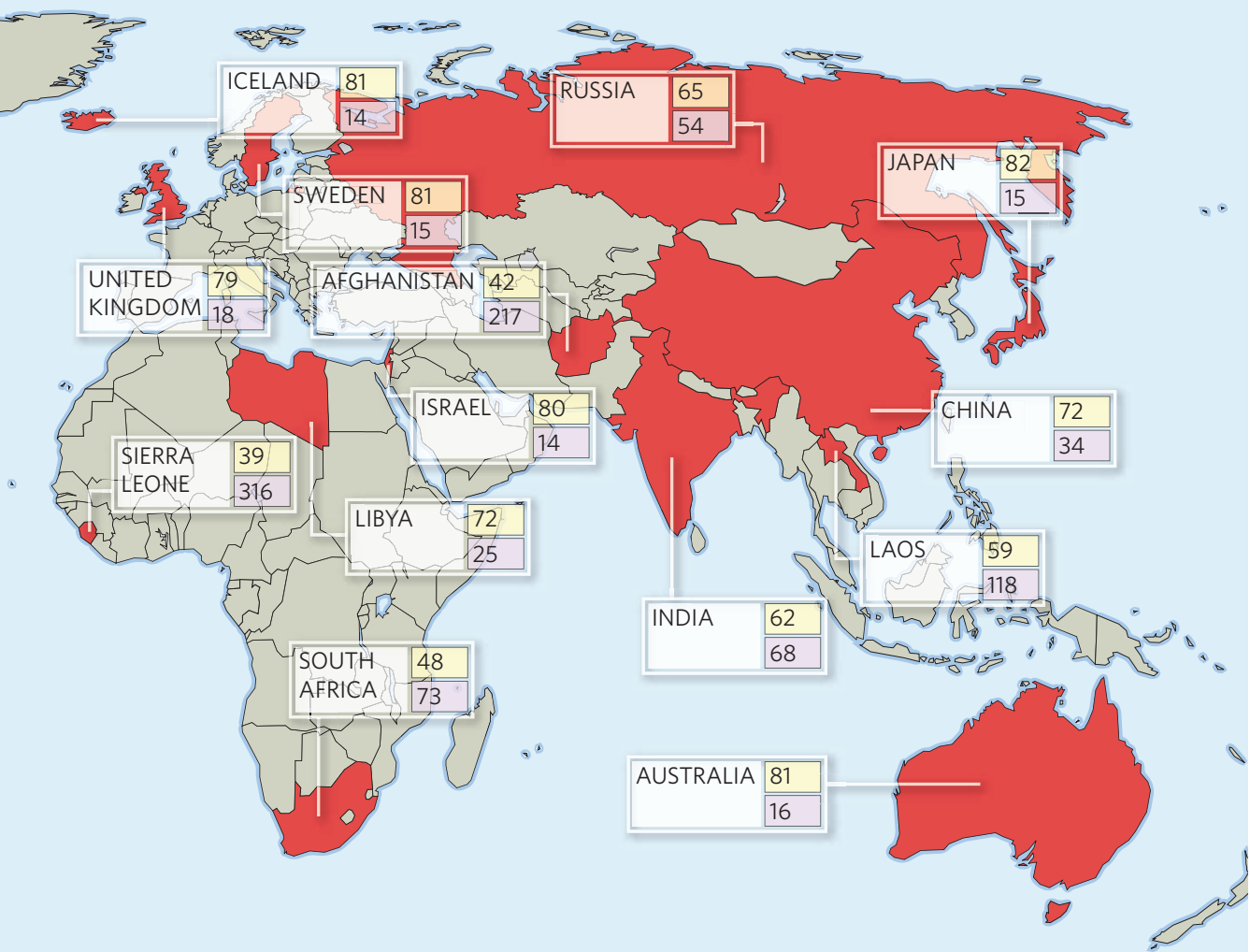

\section{ZOO NEWS}

\section{Big and cold}

Directors of the Alaska Zoo in

Anchorage have finally agreed to move Maggie, the world's most northerly elephant, to a new, more comfortable home further south.

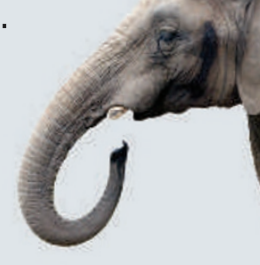

Small and hungry

Researchers at Japan's

Tohoku University in Sendai have proved that it's not just dogs that can perform pavlovian tricks.

They have trained their 'Pavlov's cockroaches' to salivate when presented with a specific nonfood odour.

\section{SCORECARD}

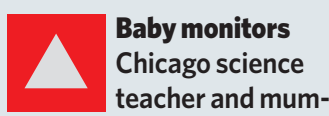
of-two Natalie Meilinger has been keeping one eye on developments aboard the shuttle Atlantis....after her baby monitor started picking up the latest images from NASA.

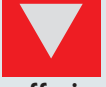

Kids with hay fever A UK study suggests that school kids suffering the summer affliction are twice as likely to drop a grade in their exams, relative to their performance in the winter 'mock' tests.

\section{ON THE RECORD}

\section{"Biking is one of the manliest pastimes on the planet, so it's bloody reassuring to know someone's taking care of our virility while we're on the road."}

Round-the-world motorcyclist Nick Sanders welcomes Swiss scientists' invention of a coating for black leather trousers that helps them to reflect heat and avoid causing fertility problems for male bikers.

Sources: Reuters, PLoS One, Associated Press, The Scotsman, Revolver Communications

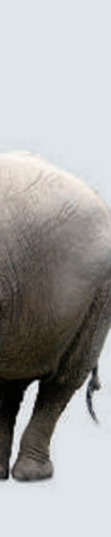

